\title{
Synthesis of nanosized ZSM-5 zeolite using extracted silica from rice husk without adding any alumina source
}

\author{
Zahra Ghasemi Laleh Vajheh Sari • \\ Habibollah Younesi · Hossein Kazemian
}

Received: 29 September 2014/ Accepted: 10 October 2014/Published online: 24 October 2014

(C) The Author(s) 2014. This article is published with open access at Springerlink.com

\begin{abstract}
The synthesis of analcime and nanosized ZSM5 zeolites was carried out by a hydrothermal method with silica extracted from rice husk, available as an inexpensive local biowaste, and without the use of an extra alumina source. Amorphous silica (with $88 \mathrm{wt} \%$ of $\mathrm{SiO}_{2}$ ) was extracted from rice husk ash by a suitable alkali solution. The effects of crystallization temperature, time and $\mathrm{SiO}_{2} /$ $\mathrm{Al}_{2} \mathrm{O}_{3}$ ratio of the initial system on the properties of final products were investigated. For the characterization of the synthesized product, X-ray diffraction, scanning electron microscope, energy dispersive X-ray techniques, Fourier transform infrared and Brunauer-Emmett-Teller method were applied. Crystallinity percentages of analcime and nanosized ZSM-5 were 95.86 and 89.56, respectively, with specific surface area of $353.5 \mathrm{~m}^{2} \mathrm{~g}^{-1}$ for ZSM-5. The experimental results revealed that the synthesis of analcime and nanosized ZSM-5 zeolites was more practical with using silica extracted from inexpensive raw materials, while the whole crystallization process was accomplished without adding any alumina source during.
\end{abstract}

Keywords Rice husk - Hydrothermal · Analcime · Nanosized ZSM-5

Z. G. L. V. Sari · H. Younesi $(\bowtie) \cdot$ H. Kazemian

Department of Environmental Science, Faculty of Natural

Resources, Tarbiat Modares University, Noor, Iran

e-mail: hunesi@modares.ac.ir; hunesi@yahoo.com

Z. G. L. V. Sari · H. Younesi · H. Kazemian

Department of Chemical and Biochemical Engineering,

Faculty of Engineering, The University of Western Ontario,

London, ON N6A 5B9, Canada

\section{Introduction}

Rice husk is a major by-product of rice processing and there are large quantities of husk produced annually in Iran. The total rice harvest reported in 2008 was 2.1 million metric tons, the processing of which produced about $30 \%$ (630 thousand tons) of rice husk as byproduct. Its disposal as an agricultural waste has become an environmental issue in many regions, so there is a stable supply of raw materials for mass production of zeolite. As source of extracted silica, rice husk is a practical, low-cost alternative to pure chemical sources, as silica rendered from rice husk is highly reactive and less selective.

Rice husk consists $70-85 \%$ of organic matter and the remainder is $\mathrm{SiO}_{2}$. The formation of rice husk ash results from its combustion in air and approximately one-fifth of the rice husk burned is converted to ash (Liou 2004). Amorphous silica can be extracted from the ash by a suitable alkali solution (Kalapathy et al. 2002). This extracted amorphous silica can be used as an alternative inexpensive silica source for preparation of silicon-based materials, which have industrial and technological potential such as MCM (Grisdanurak et al. 2003) and zeolites (Dalai et al. 1985; Loiha et al. 2009; Nur 2001; Prasetyoko et al. 2006).

The ZSM-5 is a typically high silica zeolite with a medium pore size of $0.54-0.56 \mathrm{~nm}$ formed by ten-membered rings (McCusker and Baerlocher 2007). This molecular sieve has an MFI-type structure which promotes the wide use of ZSM-5 zeolite such as for processes involving petrochemicals and fluid catalytic cracking (Grace 1980), separation of gases or liquids (van Bekkum et al. 1994), synthesis of fine chemicals (Corma and Garcia, 1997; Hlderich et al. 1991), in space research (Ghobarkar 
et al. 1999), as solid acid catalyst (Chen 2001; Corma 1995; Mota et al. 1997).

In most cases, ZSM-5 is synthesized by hydrothermal crystallization from hydrogels containing precursors of silicon and aluminum (Mohamed et al. 2005a). The crystallization process and also the crystal size and the distribution of the final products are all intricately dependent on multiple factors such as the sources of silicon and aluminum, aluminum content, crystallization temperature, crystallization time, the template/silicon ratio and on other initial conditions of the reaction system (Yu et al. 2007).

Based on the relevant role of the surface area in catalytic behavior, the small crystal size of zeolites improves the properties of the zeolites with their great external surface and short intra-granular diffusion pore channels (Ismail et al. 2006). In this study, we report an efficient route for a simple and low-cost synthesis of nanosized ZSM-5 zeolite using a cheap, abundant and renewable source of both amorphous silica and alumina, extracted from an agricultural by-product. Although rice husk, instead of silica source, has been utilized for zeolite synthesis in aforementioned studies, but nanosized ZSM-5 zeolite synthesis using silica and alumina extracted from rice husk has not yet been previously reported. Also, alumina has been used as source in most zeolite synthesis studies (Dalai et al. 1985; Hamdan et al. 1997; Katsuki et al. 2005; Loiha et al. 2009; Nur 2001). Therefore, our aim in the present study was to achieve the synthesis without adding any alumina source during the whole crystallization process to decrease the cost.

\section{Experimental}

Silica extraction from rice husk

The amorphous silica was extracted from rice husk according to Ghasemi and Younesi $(2011,2012)$ method applying a suitable alkali solution. Rice husks, obtained from a local rice processing factory in Mazandaran (a province in northern Iran), were washed with distilled water and filtered to eliminate clay particles, and then immersed in $\mathrm{HCl}$ (Merck, $37 \%$ ) solution (1 M) for $8 \mathrm{~h}$. After leaching with $\mathrm{HCl}$, the husks were washed well again with distilled water, dried in air and calcined at $700{ }^{\circ} \mathrm{C}$ for $6 \mathrm{~h}$ in constant heating rate at $10{ }^{\circ} \mathrm{C} / \mathrm{min}$. The rice husk ash obtained was then subjected to being dissolved in $\mathrm{NaOH}$ (Merck, $98 \%$ ) solution (2 M), followed by refluxing for $12 \mathrm{~h}$. Concentrated $\mathrm{HCl}$ was added to the dissolved rice husk ash to reach complete precipitation. The precipitate was filtered from the solution, washed with distilled water till free from chloride ions and finally dried at $110{ }^{\circ} \mathrm{C}$ in an oven overnight.
Table 1 Initial composition, crystallization temperature and crystallization time of samples

\begin{tabular}{|c|c|c|c|c|c|}
\hline Run & Template & $\begin{array}{l}\text { Alumina } \\
\text { sources }\end{array}$ & $\begin{array}{l}\text { Molar } \\
\text { composition of } \\
\text { initial solution } \\
\left(\mathrm{Na}_{2} \mathrm{O}: \mathrm{Al}_{2} \mathrm{O}_{3}:\right. \\
\left.\mathrm{SiO}_{2}: \text { TPA: } \mathrm{H}_{2} \mathrm{O}\right)\end{array}$ & $\begin{array}{l}\text { Time } \\
\text { (h) }\end{array}$ & $\begin{array}{l}\text { Temperature } \\
\left({ }^{\circ} \mathrm{C}\right)\end{array}$ \\
\hline S1 & TPABr & $\mathrm{Al}_{2}\left(\mathrm{SO}_{4}\right)_{3}$ & $\begin{array}{l}0.504: 40: 1: \\
0.215: 16.168\end{array}$ & 96 & 150 \\
\hline $\mathrm{S} 2$ & TPABr & $\mathrm{NaAlO}_{2}$ & $\begin{array}{l}0.504: 40: 1: \\
0.215: 16.168\end{array}$ & 96 & 150 \\
\hline S3 & TPABr & - & $\begin{array}{l}0.504: 176: 1: \\
0.215: 16.168\end{array}$ & 48 & 150 \\
\hline S4 & TPAOH & - & $\begin{array}{l}0.504: 176: 1: \\
0.215: 16.168\end{array}$ & 48 & 150 \\
\hline S5 & TPAOH & - & $\begin{array}{l}0.504: 176: 1: \\
0.215: 16.168\end{array}$ & 96 & 150 \\
\hline
\end{tabular}

\section{Zeolite preparation}

The zeolites were synthesized by hydrothermal crystallization (Fan et al. 2008) with varied $\mathrm{SiO}_{2} / \mathrm{Al}_{2} \mathrm{O}_{3}$ molar ratios, crystallization time and temperature. The synthesis conditions as well as the initial composition are summarized in Table 1. The alumina sources employed were aluminum sulfate (Scharlu), sodium aluminate (Merck) and alumina content of extracted silica from rice husk. Tetrapropylammonium hydroxide (TPAOH, $20 \%$ Fluka) and tetrapropylammonium bromide (TPABr, Merck) were used as template reagents to assist the formation of the zeolite framework.

Typically, $4.1 \mathrm{~g}$ of $\mathrm{NaOH}$ was dissolved in $69.2 \mathrm{~g}$ of $\mathrm{H}_{2} \mathrm{O}$ and then divided into two equal portions. An amount of $29.8 \mathrm{~g}$ of amorphous silica, extracted from rice husk, was completely dissolved in one portion of the $\mathrm{NaOH}$ solution and the resultant suspension was stirred until a clear solution was reached. After that, $18.3 \mathrm{~g}$ of $20 \%$ tetrapropylammonium hydroxide was added drop-wise to the sodium silicate solution while stirring. The resulting mixture was further stirred for $1 \mathrm{~h}$. An aluminate solution (if according to molar ratio, excess alumina source was necessary) was prepared by mixing $1.7 \mathrm{~g}$ of alumina with another portion of the $\mathrm{NaOH}$ solution. After achieving clearness of the solutions, the silicate solution was slowly poured into the aluminate solution while stirring vigorously. The resultant mixture was stirred for $1 \mathrm{~h}$, transferred into Teflonlined stainless steel autoclaves, and then hydrothermal synthesis was carried out at $150{ }^{\circ} \mathrm{C}$ for different crystallization periods (48 and $96 \mathrm{~h}$ ). Finally, the solid products were filtered, washed several times with distilled water until the $\mathrm{pH}$ value dropped to 8.5 , and dried in an oven at $110^{\circ} \mathrm{C}$ overnight. 


\section{Characterization}

To do the proximate analysis of rice husk, the ASTM method was used (Shuangning et al. 2006). An X-ray fluorescence (XRF, Philips PW2404 Spectrometer) was applied for determining the chemical composition of the silica powder extracted rom rice husk and the synthesized ZSM-5 zeolite. The loss of ignition (LOI) test was carried out following the SIRIM procedure (ISO 3262-1975). About $1 \mathrm{~g}$ dried sample of the extracted silica was placed in a platinum crucible and ignited in a muffled furnace at $1000{ }^{\circ} \mathrm{C}$ for $30 \mathrm{~min}$ to achieve a constant mass, followed by cooling in a desiccator. The loss of ignition, as percentage by mass, is given by the following Eq. 1:

$\mathrm{LOI}(\%)=\frac{(\mathrm{M} 0-\mathrm{M} 1)}{\mathrm{M} 0} \times 100$

where M0 is the mass of the sample and M1 the mass of the sample after ignition.

The X-ray diffraction (XRD) patterns of zeolite types and extracted silica were measured by a Philips diffractometer (X'Pert, PW1800). The patterns, were run with Nifiltered copper radiation $(K \alpha=1.5404 \AA$ A $)$ at $30 \mathrm{kV}$ voltage and $10 \mathrm{~mA}$ current with scanning speed of $2 \theta=2.5 \% \mathrm{~min}$. The crystallinity of the prepared samples was calculated using the ratio of the sum of the areas of all peaks in the whole area of the XRD diffractogram and multiplying by 100 . The average crystal size of synthesized products was calculated by Scherrer equation (Eq. 2), where: $\tau$ is the mean size of the ordered (crystalline) domains, which may be smaller or equal to the grain size; $K$ is a dimensionless shape factor, with a value close to unity. The shape factor has a typical value of about 0.9 , but varies with the actual shape of the crystallite; $\lambda$ is the X-Ray wavelength; $\beta$ is the full width at half maximum intensity (FWHM), after subtracting the instrumental line broadening, in radians and $\theta$ is the Bragg angle.

$\tau=\frac{K \lambda}{\beta \cos \theta}$

The scanning electron microscope (SEM, Phillips XL30, operated at $30 \mathrm{kV}$ ) was applied for determining the morphology and size of the prepared materials. Prior to placing into the microscope, the prepared materials of the zeolites were sprinkled uniformly over an adhesive tape, sputter coated with a thin layer of gold, and consequently an electron acceleration voltage of $30 \mathrm{kV}$ was applied. The $\mathrm{Si} / \mathrm{Al}$ ratio of the final nanosized ZSM-5 was determined by an energy dispersive X-ray (EDX) spectrophotometer of the abovementioned SEM.

The nitrogen adsorption/desorption isotherms were measured at $196{ }^{\circ} \mathrm{C}$ using a conventional volumetric apparatus. The specific surface area was obtained using the
BET (Brunauer-Emmett-Teller) method. The t-plot method was used for obtaining the micropore volume of the zeolites.

The Fourier transform infrared (FT-IR) spectrophotometer (Shimadzo FTIR1650, Japan) was employed to determine the presence of functional groups in the prepared materials at room temperature. Samples of $1 \mathrm{mg}$ of the prepared materials were ground with $100 \mathrm{mg}$ of $\mathrm{KBr}$ as translucent sample disks and mounted to the sample holder in the cavity of the spectrometer. The spectral changes were chosen from 400 to $4,000 \mathrm{~cm}^{-1}$.

Thermal gravimetrical analysis (TGA) was undertaken in flowing air with a temperature ramp of $10{ }^{\circ} \mathrm{C} / \mathrm{min}$ to the maximum of $800{ }^{\circ} \mathrm{C}$ using a STA-1500 Rheometric Scientific instrument.

\section{Results and discussion}

Chemical composition and XRD characterization of rice husk ash and extracted silica

The LOI amount of rice husk ash was $2.562 \%$, which corresponds to the amount of removed moisture and coexisting unburned carbon from the sample. The low LOI amount of ash indicates that the amount of the unburned carbon is small. On the other hand, the LOI amount of extracted silica powder was 10.64 . With regard to the low LOI amount of ash indicating the low amount of unburned carbon, the LOI amount of the extracted silica powder pertains almost totally to the removal of moisture. The weight percentages of $\mathrm{SiO}_{2}, \mathrm{Al}_{2} \mathrm{O}_{3}$ and $\mathrm{Na}_{2} \mathrm{O}$ in the rice husk ash and extracted silica as determined by XRF are listed in Table 2. The initial gel composition of the zeolites was calculated based on the results of the XRF analysis.

According to the XRD analysis of the ash, heat treated at $700{ }^{\circ} \mathrm{C}$ for $6 \mathrm{~h}$, the supplied rice husk ash represents its crystalline phase in the form of cristobalite, tridymite and quartz (Ghasemi and Younesi 2011; Wang et al. 2010). In this study, the crystalline form of the ash is supposed to be the result of its heating at high temperature.

The XRD analysis of the extracted silica powder indicated that it was amorphous. This amorphous form is an

Table 2 The LOI (loss of ignition) test and XRF analysis results of ash and extracted silica powder

\begin{tabular}{lll}
\hline Composition & Ash (wt\%) & Extracted silica powder (wt\%) \\
\hline $\mathrm{SiO}_{2}$ & 95.91 & 88.0 \\
$\mathrm{Al}_{2} \mathrm{O}_{3}$ & 0.19 & 0.5 \\
$\mathrm{Na}_{2} \mathrm{O}$ & - & 0.6 \\
$\mathrm{LOI}$ & 2.56 & 10.6 \\
\hline
\end{tabular}




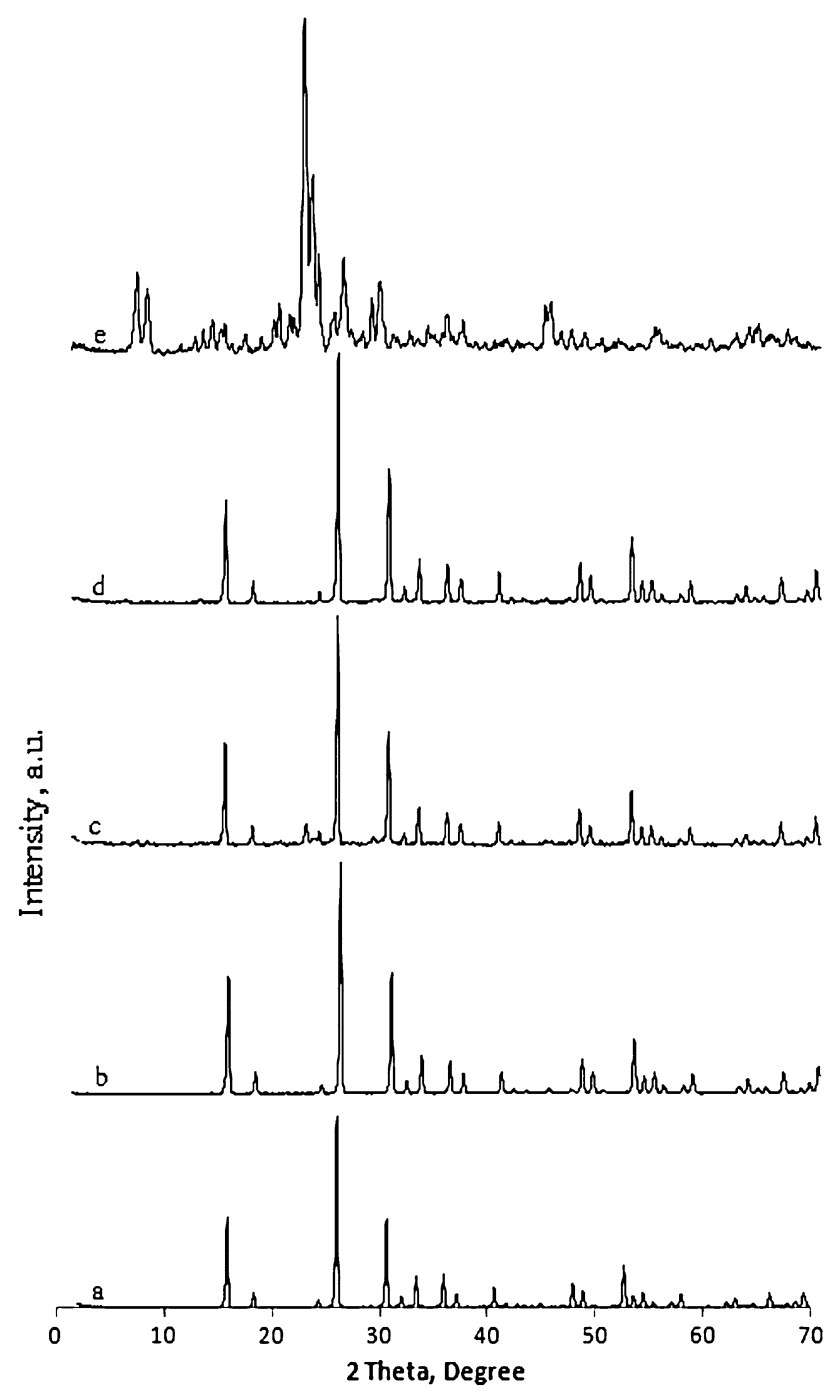

Fig. 1 XRD patterns taken with initial $\mathrm{SiO}_{2} / \mathrm{Al}_{2} \mathrm{O}_{3}$ mol ratio of a 40 after 96 h with $\mathrm{Al}_{2}\left(\mathrm{SO}_{4}\right)_{3}$, b 40 after 96 h with $\mathrm{NaAlO}_{2}$, c 176 after $48 \mathrm{~h}$ with TPABr, d 176 after $48 \mathrm{~h}$ with TPAOH and e 176 after $96 \mathrm{~h}$ with TPAOH, at $150{ }^{\circ} \mathrm{C}$

advantage toward the preparation of silicon-based materials like zeolites, because the silica is rendered active in its amorphous form to produce zeolite (Ghasemi and Younesi 2011; Wang et al. 2010).

Effects of $\mathrm{SiO}_{2} / \mathrm{Al}_{2} \mathrm{O}_{3}$ ratios and crystallization time

The $\mathrm{SiO}_{2} / \mathrm{Al}_{2} \mathrm{O}_{3}$ molar ratio in extracted silica was 176 . Further addition of the alumina sources as aluminum sulfate and sodium aluminate was mixed with sodium silicate solution in order to reach a molar ratio of 40 of $\mathrm{SiO}_{2} /$ $\mathrm{Al}_{2} \mathrm{O}_{3}$. The synthesized products were characterized by the XRD technique.

The patterns of the products synthesized with the different $\mathrm{SiO}_{2} / \mathrm{Al}_{2} \mathrm{O}_{3}$ molar ratios of 40 and 176 and the
Table 3 Effects of initial $\mathrm{SiO}_{2} / \mathrm{Al}_{2} \mathrm{O}_{3}$ mol ratio and synthesis time on the crystallization process at $150{ }^{\circ} \mathrm{C}$

\begin{tabular}{lcllll}
\hline Run & $\begin{array}{l}\mathrm{SiO}_{2} / \\
\mathrm{Al}_{2} \mathrm{O}_{3} \\
\text { ratio }\end{array}$ & $\begin{array}{l}\text { Time } \\
\text { (h) }\end{array}$ & $\begin{array}{l}\text { Phase } \\
\text { formed }\end{array}$ & $\begin{array}{l}\text { XRD average } \\
\text { crystal size (nm) }\end{array}$ & $\begin{array}{l}\text { XRD } \\
\text { crystallinity } \\
(\%)\end{array}$ \\
\hline $\mathrm{S} 1$ & 40 & 96 & Analcime & 115.7 & 92.13 \\
$\mathrm{~S} 2$ & 40 & 96 & Analcime & - & 94 \\
$\mathrm{~S} 3$ & 176 & 48 & Analcime & - & 92.27 \\
$\mathrm{~S} 4$ & 176 & 48 & Analcime & 205.1 & 95.86 \\
$\mathrm{~S} 5$ & 176 & 96 & ZSM-5 & 25.1 & 89.56 \\
\hline
\end{tabular}

crystallization times of 48 and 96 at $150{ }^{\circ} \mathrm{C}$ are shown in Fig. 1. The results containing the phase formed, average crystal size and the percentage of the crystallinity of the products are summarized in Table 3.

As the table shows, with a $\mathrm{SiO}_{2} / \mathrm{Al}_{2} \mathrm{O}_{3}$ molar ratio of 40 , the ZSM-5 zeolite could not be synthesized. It is clear that the $\mathrm{SiO}_{2} / \mathrm{Al}_{2} \mathrm{O}_{3}$ molar ratio of 40 is not suitable for ZSM-5 zeolite synthesis using this silica source. The analcime phase exists at the $\mathrm{SiO}_{2} / \mathrm{Al}_{2} \mathrm{O}_{3}$ molar ratio of 40 (Fig. 1a, b). Peaks at $2 \theta=15.81,25.96$ and 30.54 (Treacy and Higgins 2007a) confirm that it was a pure phase of analcime zeolite that was produced. The results of the product synthesized using aluminum sulfate and sodium aluminate at $150{ }^{\circ} \mathrm{C}$ with the $\mathrm{SiO}_{2} / \mathrm{Al}_{2} \mathrm{O}_{3}$ molar ratio of 40 show the existence of an analcime phase. The reason is that the crystallization rate for the formation of ZSM-5 increases as the aluminum content decreases with a $\mathrm{SiO}_{2} / \mathrm{Al}_{2} \mathrm{O}_{3}$ ratio above 100 (Cheng et al. 2001; Szostak 1989). In addition, the silica obtained from rice husk needs to be depolymerized so that the structure of the zeolite is formed. The agent responsible for this step is $\mathrm{OH}^{-} / \mathrm{Si}$ ratio, which at the initial mole ratio of $\mathrm{S} 1$ and $\mathrm{S} 2$, is not suitable for depolymerizing the silica source enough to produce ZSM-5 zeolite. The double-five-ring (D5R) silicates in ZSM-5 zeolite structure increased with decreasing $\mathrm{OH}^{-} / \mathrm{Si}$ ratio (Lechert 2000; van Santen et al. 1986). Therefore, we need high $\mathrm{SiO}_{2} / \mathrm{Al}_{2} \mathrm{O}_{3}$ mole ratio increasing silica source to synthesis ZSM-5 zeolite.

The XRD pattern of the products obtained at $150{ }^{\circ} \mathrm{C}$ after $48 \mathrm{~h}$ with $\mathrm{SiO}_{2} / \mathrm{Al}_{2} \mathrm{O}_{3}$ molar ratio of 176 is shown in Fig. $1 \mathrm{c}$ and $\mathrm{d}$, which indicates the formation of a pure phase of analcime zeolite. The percentage of crystallinity of synthesized analcime in the sample S4 is the highest. The pattern of the product synthesized by the $\mathrm{SiO}_{2} / \mathrm{Al}_{2} \mathrm{O}_{3}$ molar ratio of 176 after $96 \mathrm{~h}$ at $150{ }^{\circ} \mathrm{C}$ shows that only the pure phase of ZSM-5 zeolite exists (Fig. 1e). The XRD pattern of the sample indicated that a highly crystallized ZSM-5 zeolite was formed without impurities. Peaks at $2 \theta=7.94,8.01$ and 8.90 (Treacy and Higgins 2007b) confirm that it was a pure phase of ZSM-5 zeolite that was 
produced. The reason is that zeolites are thermodynamically metastable phases. The formation of metastable phases of zeolites depends on temperature, and then the most stable phase will continue to grow and be detected finally (Yu et al. 2007). The crystallization time plays an important role in the formation of the specific metastable phase of zeolite. The crystallization time is a significant parameter in the synthesis of zeolites. In this study, by increasing the reaction time from 48 to $96 \mathrm{~h}$, the pure phase of ZSM-5 zeolite was obtained with the initial $\mathrm{SiO}_{2} / \mathrm{Al}_{2} \mathrm{O}_{3}$ molar ratio of 176. Chareonpanich et al. (2004) noted that the longer the holding time the greater the yield of ZSM-5 crystalline zeolite, using fly ash as silica source.

The maximum crystallinity of ZSM-5 zeolite at $89.56 \%$ was obtained at a $\mathrm{SiO}_{2} / \mathrm{Al}_{2} \mathrm{O}_{3}$ molar ratio of 176 . According to the results of this study, crystallization time and the aluminum content of initial system play important roles in the formation of the ZSM-5 zeolite using extracted silica from rice husk. The ZSM-5 zeolite was produced by increasing crystallization time and decreasing the aluminum content of initial system, which increases the crystallization rate.

Chareonpanich et al. (2004) synthesized ZSM-5 zeolite with initial $\mathrm{SiO}_{2} / \mathrm{Al}_{2} \mathrm{O}_{3}$ molar ratio of 40 at $210{ }^{\circ} \mathrm{C}$ after $4 \mathrm{~h}$ with the initial pressure of 4 bars using nitrogen gas. Panpa and Jinawath (2009) reported that the initial system with $\mathrm{SiO}_{2} / \mathrm{Al}_{2} \mathrm{O}_{3}$ molar ratios less than 80 produced an amorphous phase of poorly crystalline ZSM-5 zeolite using rice husk ash as silica source and sodium aluminate as alumina source. They found that the gels with $\mathrm{SiO}_{2} / \mathrm{Al}_{2} \mathrm{O}_{3}$ molar ratios ranging from 80 to 200 favored crystalline ZSM-5 zeolite production.

As mentioned above, there are some studies dealing with zeolite synthesis using rice husk ash as an alternative silica source (Dalai et al. 1985; Hamdan et al. 1997; Katsuki et al. 2005; Loiha et al. 2009; Nur 2001). Kordatos et al. (2008) used rice husk ash as silica source for the synthesis of ZSM-5 zeolite (Kordatos et al. 2008). Mohamed et al. (2008) and Othman Ali et al. (2011) synthesized ZSM-5 zeolite using rice husk ash as silica source and aluminum sulfate as alumina source. The most mentioned studies added a special alumina source in the initial system for the synthesis of ZSM-5, whereas we synthesized analcime and nanosized ZSM-5 zeolite using extracted silica from rice husk, without adding any external alumina source, using the alumina content of the extracted silica.

In the present study, the results of XRD confirmed the actual synthesis of analcime and nanosized ZSM-5 zeolites with silica extracted from rice husk as silica source. The extracted silica prepared in this study was amorphous, whereas the silica source of the abovementioned paper was
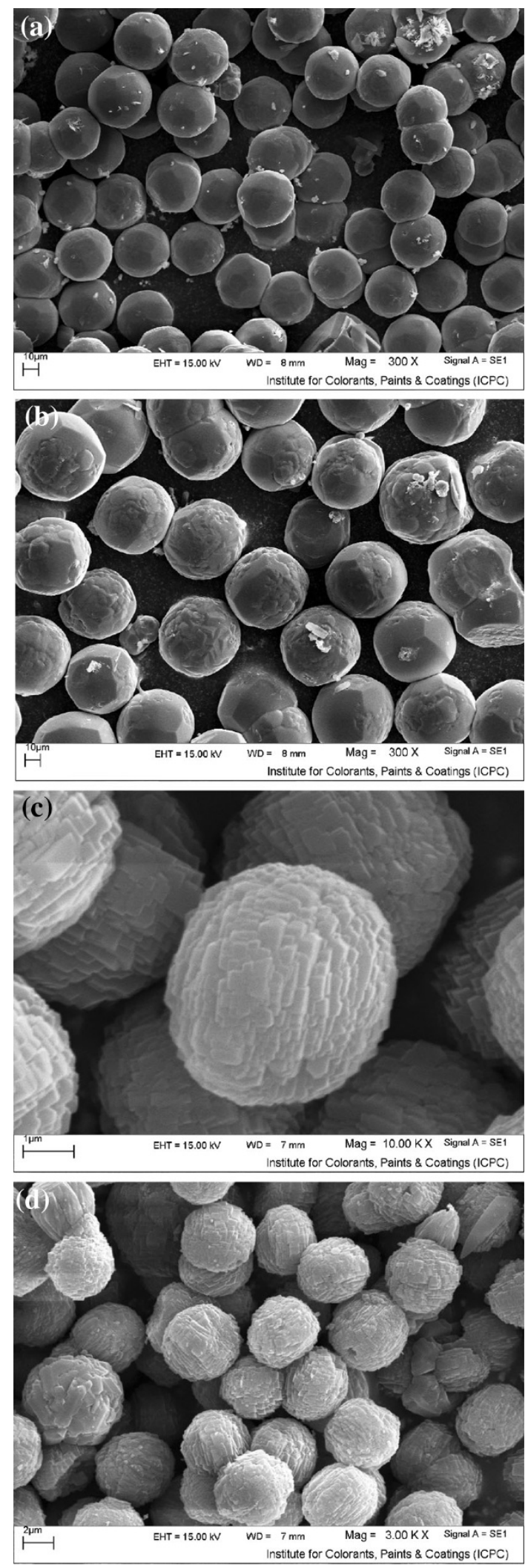

Fig. 2 SEM micrographs of products in sample a S1, b S2, c and d S5 
crystalline. The silica is active in its amorphous form for producing zeolite. The analcime and ZSM-5 zeolites were prepared without adding any alumina source and, in the case of ZSM-5, with nanosized crystal, which has not yet been reported, to our knowledge. The synthesis of nanosized ZSM-5 at initial high $\mathrm{SiO}_{2} / \mathrm{Al}_{2} \mathrm{O}_{3}$ molar ratios favored the crystallization rate, since the crystallization rate increased for the formation of ZSM-5 as the aluminum content decreased with a $\mathrm{SiO}_{2} / \mathrm{Al}_{2} \mathrm{O}_{3}$ ratio above 100 (Szostak 1989). This was one key route for the synthesis of nanosized ZSM-5 zeolite in this study.

\section{SEM and EDX analysis of products}

The scanning electron microscopy images recorded for the as-synthesized zeolite samples are presented in Fig. 2. The SEM micrographs of the hydrothermal products show their morphologies under different synthesizing conditions. The Fig. $2 \mathrm{a}, \mathrm{b}$ shows products in samples S1 and S2 where well crystalline analcime type of zeolites, with a spherical shape and uniform size, were obtained. Only the crystals of the ZSM-5 zeolite were found after $96 \mathrm{~h}$. The SEM micrograph of the prepared ZSM-5 zeolite is shown in Fig. 2c, d, which shows that this zeolite crystallizes in spherical-shaped crystals (Mohamed et al. 2005b).

The diameter of spherical shape particles of prepared ZSM-5 zeolite is $<6 \mu \mathrm{m}$ according to the SEM picture. However, the calculated crystalline size of the crystal on the basis of X-ray data using Scherer equation is $25.1 \mathrm{~nm}$. Crystalline size calculated from Scherer equation refers to the size of a single crystal of ZSM-5 framework while, a particle could be polycrystalline. The particle size is equal to crystal size if every particle is a single crystal. In the present study, the zeolite particles are polycrystalline and crystal size is submultiple of particle size (Ismail et al. 2006; Wang et al. 2010).

Typically, ZSM-5 zeolite is synthesized with the framework Si/Al ratio of $>5$ (Yu et al. 2007). The $\mathrm{Si} / \mathrm{Al}$ and $\mathrm{Na}_{2} \mathrm{O} / \mathrm{SiO}_{2}$ ratios resulting in prepared ZSM-5 zeolite were determined by EDX technique as 14.8 and 0.01, respectively.

Surface texture of synthesized analcime zeolite and ZSM-5

The analcime and ZSM-5 crystals were characterized using $\mathrm{N}_{2}$ adsorption/desorption to determine their pore volume and surface area. The isotherm and the pore size distribution curve of prepared ZSM-5 and the BJH-Plot of (a)

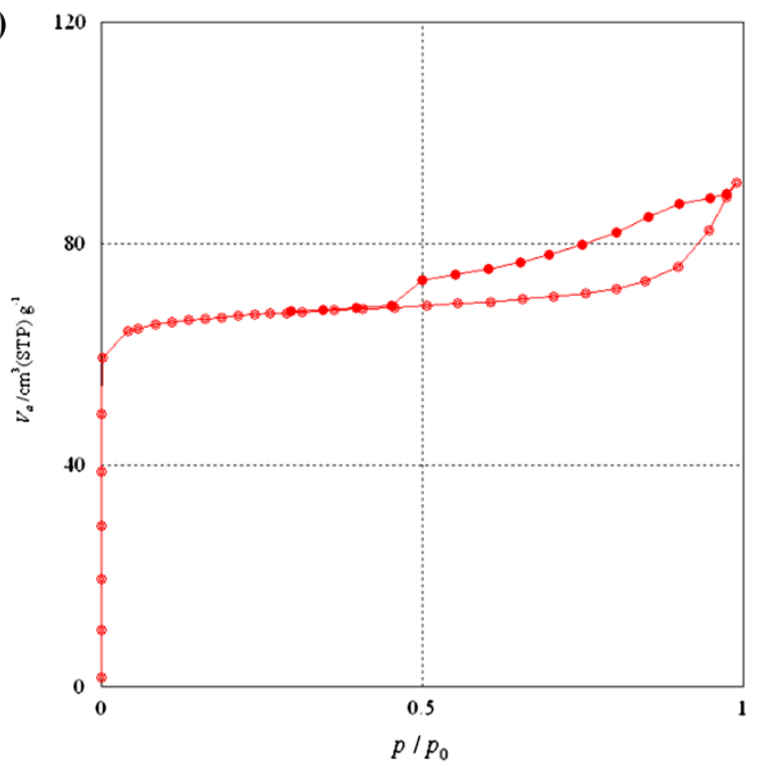

(b)

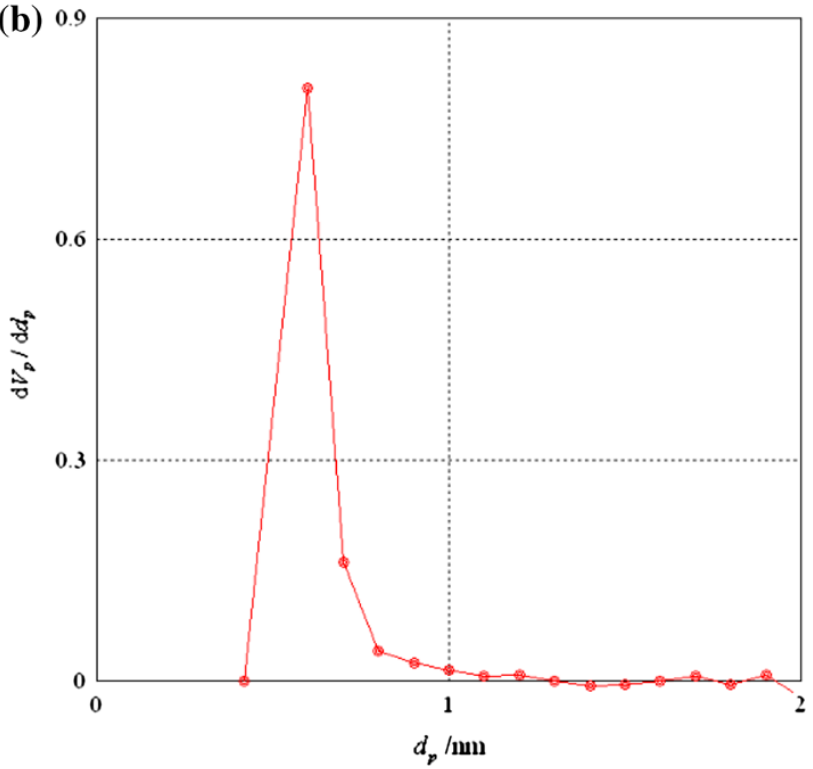

Fig. 3 a The $N_{2}$ adsorption/desorption isotherm and $\mathbf{b}$ the pore size distribution curve of prepared ZSM-5

Table 4 Surface texturing data of analcime and ZSM-5 zeolites prepared from rice husk

\begin{tabular}{llllll}
\hline Run & $\begin{array}{l}\text { BET } \\
\text { surface } \\
\text { area } \\
\left(\mathrm{m}^{2} / \mathrm{g}\right)\end{array}$ & $\begin{array}{l}\text { Total } \\
\text { pore } \\
\text { volume } \\
\left(\mathrm{m}^{3} / \mathrm{g}\right)\end{array}$ & $\begin{array}{l}\text { Micropore } \\
\text { volume } \\
\left(\mathrm{m}^{3} / \mathrm{g}\right)\end{array}$ & $\begin{array}{l}\text { Microporosity } \\
(\%)\end{array}$ & $\begin{array}{l}\text { Size of } \\
\text { micropores } \\
(\mathrm{nm})\end{array}$ \\
\hline $\mathrm{S} 4$ & 0.0485 & 0.002 & 0.001 & 59.2 & - \\
$\mathrm{S} 5$ & 353.53 & 0.141 & 0.136 & 96.4 & 0.53 \\
\hline a Microporosity & \multicolumn{2}{l}{ percentages $=$ (Micropore } & volume/Total pore
\end{tabular}




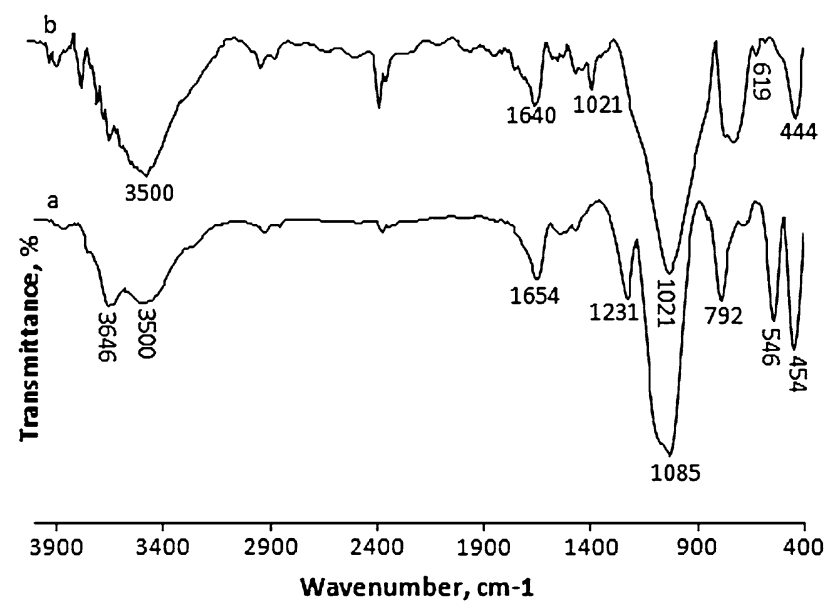

Fig. 4 FTIR spectra in the $400-4,000 \mathrm{~cm}^{-1}$ range for prepared a ZSM-5 and b analcime (81.3254\%)

analcime zeolite with the highest crystallinity (Sample S4) are shown in Fig. 3a, b and c.

The $\mathrm{N}_{2}$ adsorption/desorption isotherm of ZSM-5 zeolite with an initial $\mathrm{SiO}_{2} / \mathrm{Al}_{2} \mathrm{O}_{3}$ molar ratio of 176 and analcime zeolite with the highest crystallinity (SampleS4) were measured at $196{ }^{\circ} \mathrm{C}$. The isotherm of ZSM-5 zeolite consists of a sharp knee at P/P0 lower than 0.1 due to the filling of micropores. The parameters, including the BET surface area, total pore volume, micropore volume, microporosity percentages, and size of micropores, obtained from BET equation and t-plot method, are summarized in Table 4. The specific surface area and micropore volume of ZSM-5 were $353.5 \mathrm{~m}^{2} \mathrm{~g}^{-1}$ and $0.1 \mathrm{~cm}^{3} \mathrm{~g}^{-1}$, respectively. The mean size of micropores in the zeolite inferred from the curve was estimated to be about $0.5 \mathrm{~nm}$, as shown in Fig. 3b.

FT-IR analysis of synthesized analcime zeolite and ZSM-5

The FT-IR spectra in the $400-4,000 \mathrm{~cm}^{-1}$ range of the highest yielding samples of analcime (S4) and ZSM-5 (S5) zeolite are shown in Fig. 4. The IR spectrum of as-synthesized ZSM-5 (Fig. 4a) is typical of pentasil zeolites. The band at $454 \mathrm{~cm}^{-1}$ is characteristic of the $\mathrm{T}-\mathrm{O}$ bending vibration of the $\mathrm{SiO}_{4}$ and $\mathrm{AlO}_{4}$ internal tetrahedral (Ismail et al. 2006). The well-defined IR bands at $792 \mathrm{~cm}^{-1}$ and that in the $1,085 \mathrm{~cm}^{-1}$ region are attributed to external symmetrical and internal asymmetrical stretching bands of $\mathrm{T}-\mathrm{O}-\mathrm{T} \quad \mathrm{T}=\mathrm{Si}, \mathrm{Al})$, while the vibrational band at $546 \mathrm{~cm}^{-1}$ (double ring vibration) confirms the presence of a five-membered ring of the pentasil structure (Ismail et al. 2006). Additional evidence for the nanosized ZSM-5 zeolite was the asymmetric stretch vibration of the band at $1,231 \mathrm{~cm}^{-1}$, which has been attributed to external linkages
Table 5 The chemical composition of synthesized ZSM-5 zeolites prepared from rice husk

\begin{tabular}{lllll}
\hline Composition & $\mathrm{Na}_{2} \mathrm{O}$ & $\mathrm{MgO}$ & $\mathrm{Al}_{2} \mathrm{O}_{3}$ & $\mathrm{SiO}_{2}$ \\
\hline wt $(\%)$ & 0.583 & 0.014 & 6.128 & 93.275 \\
\hline
\end{tabular}

(between TO4 tetrahedral) and is a structure-sensitive IR band of the ZSM-5 zeolite (Cheng et al. 2005). The bands at 3,500 and $3,646 \mathrm{~cm}^{-1}$ are due to hydroxyl groups (hydrogen bonded $\mathrm{Si}-\mathrm{OH}$ groups). The well-defined band at $1,654 \mathrm{~cm}^{-1}$ is ascribed to $\mathrm{OH}$ bending vibration, since it coexists with the $\mathrm{OH}$ stretching vibration positioned at $3,500 \mathrm{~cm}^{-1}$ (Ismail et al., 2006). Thus, the ZSM-5 zeolite was confirmed by the FT-IR technique.

The IR spectrum of analcime products with the highest crystallinity is shown in Fig. 4b. In the region of $\mathrm{OH}$ stretching vibration analcime showed absorption bands around $3,500 \mathrm{~cm}^{-1}$ and a band at $3,622 \mathrm{~cm}^{-1}$, which is attributed to a free $\mathrm{OH}$ stretching vibration. An absorption band at $1,640 \mathrm{~cm}^{-1}$ is due to the bending vibration of an adsorbed water molecule. Vibration bands in a region of TO4 tetrahedral units of zeolite at about 1,021, 737, 619 and $444-460 \mathrm{~cm}^{-1}$ are asymmetric stretching, symmetric stretching, double ring and $\mathrm{T}-\mathrm{O}$ bending vibrations, respectively (Breck 1974).

\section{XRF analysis of synthesized ZSM-5}

The results of the XRF analysis of synthesized ZSM-5 zeolite prepared from rice husk are listed in Table 5. As the table shows, the $\mathrm{SiO}_{2} / \mathrm{Al}_{2} \mathrm{O}_{3}$ and $\mathrm{Na}_{2} \mathrm{O} / \mathrm{SiO}_{2}$ ratios of prepared ZSM-5 are 15.22 and 0.006 , respectively. These results are almost the same as the results of EDX analysis and confirm it. In this study, zeolite ZSM-5 was prepared with the initial $\mathrm{SiO}_{2} / \mathrm{Al}_{2} \mathrm{O}_{3}$ molar ratio of 176 . There is no quantitative correlation between the $\mathrm{Si} / \mathrm{Al}$ ratio in the initial reaction system and that in the final product. Therefore, the $\mathrm{Si} / \mathrm{Al}$ ratio in the zeolite product cannot be adjusted simply by varying the $\mathrm{Si} / \mathrm{Al}$ ratio in the initial reaction mixture (Yu et al. 2007).

\section{Thermogravimetric thermal analysis}

Thermogravimetric analysis was carried out to determine the removal rate of water and template content of the zeolites. TGA curve of the prepared ZSM-5 is shown in Fig. 5. This figure suggests that behavior in exotherm can be due to the decomposition of the TPA cations trapped in the channels of ZSM-5. Our finding also indicated that an endotherm representing water loss was overshadowed by the exotherms due to combustion of the template. The observed significant weight losses in the temperature range 


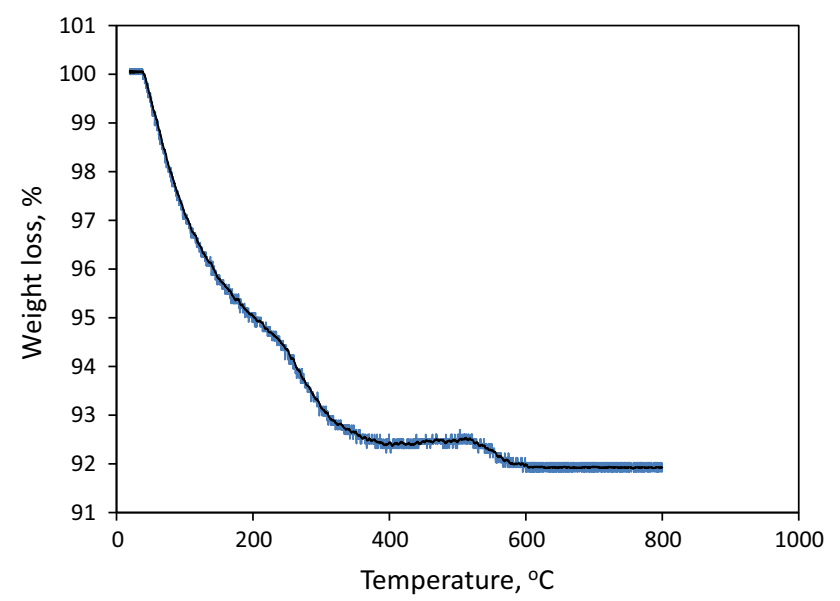

Fig. 5 TGA analysis of the prepared ZSM-5 zeolite carried out in a flow of air

20-600 ${ }^{\circ} \mathrm{C}$ indicate water loss as well as loss of template, showing an approximate estimation of the degree of crystallinity of ZSM-5 zeolite sample. Dehydration occurred below $300{ }^{\circ} \mathrm{C}$. The weight loss in the temperature ranges of 20-300 ${ }^{\circ} \mathrm{C}$ represented by a broad region in the thermogram is believed to be due to water loss. ZSM-5 zeolite has low aluminum content and less water is present in the zeolites with low aluminum content. This is because the acidity of the zeolite decreases with increasing $\mathrm{Si} / \mathrm{Al}$ ratio, thus increasing its hydrophobic nature (Shirazi et al. 2008). The weight loss in the temperature range of $300-600{ }^{\circ} \mathrm{C}$ can be attributed to TPA cation.

\section{Economical advantages}

Amorphous silica extracted from plant raw material has a number of important advantages when compared with silica of mineral origin. In particular, the processing steps are relatively simple since each plant species has a constant chemical composition, and the extracted silica from plant sources contains a narrow range of metal oxide impurities (Zemnukhova et al. 2006).

The twenty percent ash content of rice husk (Liou 2004) that was produced also in our study makes this by-product utilization increasingly attractive economically. About $88 \mathrm{~g}$ of silica was extracted per $100 \mathrm{~g}$ of rice husk ash (Table 1). In our study, $8.4 \mathrm{~g}$ of extracted silica yielded $2.8 \mathrm{~g}$ analcime and approximately $3.5 \mathrm{~g}$ nanosized ZSM-5 zeolite. According to these results, about $59.4 \mathrm{~kg}$ of analcime and $73.81 \mathrm{~kg}$ of nanosized ZSM-5 can be produced per ton of rice husk, in addition considering the low cost of rice husk. Therefore, utilization of this agricultural byproduct for analcime and nanosized ZSM-5 zeolites synthesis would result in the conversion of a low-cost raw material into a high value added product.

\section{Conclusion}

In the present study, rice husk an agricultural waste, instead of pure chemicals was used as a silica source for the synthesis of analcime and ZSM-5 zeolites. Amorphous extracted silica powder was composed of $87.988 \mathrm{wt} \% \mathrm{SiO}_{2}$ according to XRF technique. We successfully achieved the synthesis of analcime zeolite and nanosized ZSM-5 with extracted silica without using any additional alumina source. Also, the effect on the properties of the final products of crystallization temperature, crystallization time and the $\mathrm{SiO}_{2} / \mathrm{Al}_{2} \mathrm{O}_{3}$ molar ratio of the initial system were investigated. With an initial $\mathrm{SiO}_{2} / \mathrm{Al}_{2} \mathrm{O}_{3}$ ratio of 176 at $150{ }^{\circ} \mathrm{C}$, analcime and nanosized ZSM-5 zeolites were obtained after 48 and $96 \mathrm{~h}$, respectively. Crystallinity percentages of analcime zeolite and the nanosized ZSM-5 were 95.86 and 89.56 , respectively, with the specific surface area of $353.53 \mathrm{~m}^{2} \mathrm{~g}^{-1}$ for ZSM-5.

Our environmentally friendly process reduced the costs of the synthesis effectively through utilization of low cost raw materials.

Acknowledgments This study was supported by a research grant from Tarbiat Modares University (TMU), Iran Nanotechnology Initiative Council and SPAG Zeolite R\&D Group. The authors wish to thank Mr. F. Farhadi, Mr. M. Sardari and Dr. I. Sourinejad for their technical assistance during the experiments and Ellen Vuosalo Tavakoli for final editing of the English text.

Open Access This article is distributed under the terms of the Creative Commons Attribution License which permits any use, distribution, and reproduction in any medium, provided the original author(s) and the source are credited.

\section{References}

Breck DW (1974). Zeolite Molecular Sieves London: Wiley

Chareonpanich M, Namto T, Kongkachuichay P, Limtrakul J (2004) Synthesis of ZSM-5 zeolite from lignite fly ash and rice husk ash. Fuel Process Technol 85(15):1623-1634

Chen NY (2001) Personal perspective of the development of para selective ZSM-5 Catalysts. Ind Eng Chem Res 40(20): 4157-4161

Cheng M, Tan D, Liu X, Han X, Bao X, Lin L (2001) Effect of aluminum on the formation of zeolite MCM-22 and kenyaite. Microporous Mesoporous Mater 42(2-3):307-316

Cheng Y, Wang L-J, Li J-S, Yang Y-C, Sun X-Y (2005) Preparation and characterization of nanosized ZSM-5 zeolites in the absence of organic template. Mater Lett 59(27):3427-3430

Co Grace (1980) Method of analysis for fluid cracking catalysts. davison chemicals. Baltimore, MD

Corma A (1995) Inorganic solid acids and their use in acid-catalyzed hydrocarbon reactions. Chem Rev 95(3):559-614

Corma A, Garcia H (1997) Organic reactions catalyzed over solid acids. Catal Today 38(3):257-308

Dalai AK, Rao MS, Gokhale KVGK (1985) Synthesis of NaX zeolite using silica from rice husk ash. Ind Eng Chem Prod Res Develop 24(3):465-468 
Fan W, Morozumi K, Kimura R, Yokoi T, Okubo T (2008) Synthesis of nanometer-sized sodalite without adding organic additives. Langmuir 24(13):6952-6958

Ghasemi Z, Younesi H (2011) Preparation and characterization of nanozeolite naa from rice husk at room temperature without organic additives. J Nanomater 2011:1-8

Ghasemi Z, Younesi H (2012) Preparation of free-template nanometer-sized $\mathrm{Na}-\mathrm{A}$ and $-\mathrm{X}$ zeolites from rice husk ash. Waste Biomass Valor 3(1):61-74

Ghobarkar H, Schaf O, Guth U (1999) Zeolites-from kitchen to space. Prog Solid State Chem 27(2-4):29-73

Grisdanurak N, Chiarakorn S, Wittayakun J (2003) Utilization of mesoporous molecular sieves synthesized from natural source rice husk silica to chlorinated volatile organic compounds (CVOCs) adsorption. Korean J Chem Eng 20(5):950-955

Hamdan H, Muhid MNM, Endud S, Listiorini E, Ramli Z (1997) 29Si MAS NMR, XRD and FESEM studies of rice husk silica for the synthesis of zeolites. J Non-Cryst Solids 211(1-2): 126-131

Hlderich WF, Bekkum Hv, H. van Bekkum EMF, Jansen JC (1991). Chap 16 "Zeolites in organic syntheses". In: studies in surface science and catalysis: Elsevier, pp 631-726

Ismail AA, Mohamed RM, Fouad OA, Ibrahim IA (2006) Synthesis of nanosized ZSM-5 using different alumina sources. Cryst Res Technol 41(2):145-149

Kalapathy U, Proctor A, Shultz J (2002) An improved method for production of silica from rice hull ash. Bioresour Technol 85(3):285-289

Katsuki H, Furuta S, Watari T, Komarneni S (2005) ZSM-5 zeolite/ porous carbon composite: conventional- and microwave-hydrothermal synthesis from carbonized rice husk. Microporous Mesoporous Mater 86(1-3):145-151

Kordatos K, Gavela S, Ntziouni A, Pistiolas KN, Kyritsi A, Kasselouri-Rigopoulou V (2008) Synthesis of highly siliceous ZSM-5 zeolite using silica from rice husk ash. Microporous Mesoporous Mater 115(1-2):189-196

Lechert H (2000) Possibilities and limitations of the prediction of the $\mathrm{Si} / \mathrm{Al}$ ratios of zeolites from the batch composition. Microporous Mesoporous Mater 40(1-3):181-196

Liou T-H (2004) Preparation and characterization of nano-structured silica from rice husk. Mater Sci Eng A 364(1-2):313-323

Loiha S, Prayoonpokarach S, Songsiriritthigun P, Wittayakun J (2009) Synthesis of zeolite beta with pretreated rice husk silica and its transformation to ZSM-12. Mater Chem Phys 115(2-3): $637-640$

McCusker LB, Baerlocher C (2007) Zeolite structures. In: HvBAC Jirí Cejka and $\mathrm{S}$ Ferdi (eds) Studies in surface science and catalysis, 2nd edn Elsevier, pp 13-37

Mohamed RM, Aly HM, El-Shahat MF, Ibrahim IA (2005a) Effect of the silica sources on the crystallinity of nanosized ZSM-5 zeolite. Microporous Mesoporous Mater 79(1-3):7-12
Mohamed RM, Fouad OA, Ismail AA, Ibrahim IA (2005b) Influence of crystallization times on the synthesis of nanosized ZSM-5. Mater Lett 59(27):3441-3444

Mohamed MM, Zidan FI, Thabet M (2008) Synthesis of ZSM-5 zeolite from rice husk ash: characterization and implications for photocatalytic degradation catalysts. Microporous Mesoporous Mater 108(1-3): 193-203

Mota CJA, Esteves PM, Ramirez-Solis A, Hern i LR (1997) Protonated isobutane. A theoretical ab initio study of the isobutonium cations. J Am Chem Soc 119(22):5193-5199

Nur H (2001) Direct synthesis of NaA zeolite from rice husk and carbonaceous rice husk ash. Indones J Agric Sci 1(1):40-45

Othman Ali I, Hassan AM, Shaaban SM, Soliman KS (2011) Synthesis and characterization of ZSM-5 zeolite from rice husk ash and their adsorption of $\mathrm{Pb} 2+$ onto unmodified and surfactant-modified zeolite. Sep Purif Technol 83:38-44

Panpa W, Jinawath S (2009) Synthesis of ZSM-5 zeolite and silicalite from rice husk ash. Appl Catal B 90(3-4):389-394

Prasetyoko D, Ramli Z, Endud S, Hamdan H, Sulikowski B (2006) Conversion of rice husk ash to zeolite beta. Waste Manag 26(10):1173-1179

Shirazi L, Jamshidi E, Ghasemi MR (2008) The effect of Si/Al ratio of ZSM-5 zeolite on its morphology, acidity and crystal size. Cryst Res Technol 43(12):1300-1306

Shuangning X, Zhihe L, Baoming L, Weiming Y, Xueyuan B (2006) Devolatilization characteristics of biomass at flash heating rate. Fuel 85:664-670

Szostak R (1989) Molecular sieves: principles of synthesis and identification. Van Nostrand Reinhold, NY

Treacy MMJ, Higgins JB (2007a) Analcime. Collection of simulated XRD powder patterns for zeolites (fifth). Elsevier Science B.V, Amsterdam, pp 52-53

Treacy MMJ, Higgins JB (2007b) ZSM-5, Calcined. Collection of simulated XRD powder patterns for zeolites (fifth). Elsevier Science B.V, Amsterdam, pp 278-279

van Bekkum H, Geus ER, Kouwenhoven HW, J.C. Jansen MScHGK, Weitkamp J (1994). Supported zeolite systems and applications. In: Studies in surface science and catalysis: Elsevier, pp 509-542

van Santen RA, Keijsper J, Ooms G, Kortbeek AGTG (1986). The role of interfacial energy in Zeolite synthesis. In: AI Y. Murakami and JW Ward (eds) Studies in surface science and catalysis Elsevier, pp 169-175

Wang D, Li X, Liu Z, Zhang Y, Xie Z, Tang Y (2010) Hierarchical structured ZSM-5 zeolite of oriented nanorods and its performance in the alkylation of phenol with isopropanol. J Colloid Interface Sci 350(1):290-294

Yu J, Jir C, Corma HvBA, Ferdi S (2007). Synthesis of zeolites. In: Studies in surface science and catalysis Chap 3. Elsevier, pp 39-103

Zemnukhova L, Egorov A, Fedorishcheva G, Barinov N, Sokol'nitskaya T, Botsul A (2006) Properties of amorphous silica produced from rice and oat processing waste. Inorg Mater 42(1):24-29 